\title{
Correlation between LDL-cholesterol and C-reactive protein among an apparently healthy population in the city of Athens
}

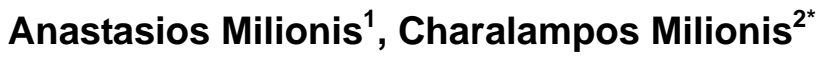 \\ ${ }^{1}$ Social Insurance Institute-Regional Branch of N. Kosmos, (Department of Endocrinology), Athens, Greece; \\ ${ }^{2}$ General Hospital of Karpenisi-Health Centre of D. Fragista, Karpenisi, Greece; *Corresponding Author: pesscharis@hotmail.com
}

Received 23 March 2011; revised 5 May 2011; accepted 10 May 2011.

\section{ABSTRACT}

Background: The atherogenic LDL is an important generative cause for the endothelial dysfunction and the configuration of the atherosclerotic lesions. CRP is a sensitive marker of inflammation on the vascular wall, but also seems to participate in the atheromatic process. The correlation between LDL and CRP could form valuable guidelines for the initiation of a treatment with statins for individuals with an increased risk of ischemic incidents. Objectives: The aim of the study was to investigate a possible correlation between LDL and CRP in an important number of apparently healthy individuals. Methods: The study material consisted of the test results of $\mathbf{2 6 0}$ male and 484 female adults with normal LDL levels who were clinically healthy. The correlation between the LDL and the CRP values of this group was investigated in this group and CRP was compared with the respective values of a group of 60 male and 204 female adults with elevated LDL levels. Results: It was ascertained that there is not a statistically important correlation between LDL and CRP values in all groups (men, women, total) of the population with normal LDL levels. Additionally, the CRP mean values were not statistically different between the individuals with normal and raised LDL. Conclusion: A number of causes are incriminated for the results. More studies are definitely needed for the confirmation of the results, particularly if the findings could lead to the formation of guidelines for the application of a treatment in people with normal LDL levels but increased CRP levels.

Keywords: LDL-Cholesterol; C-Reactive Protein; Atherosclerosis; Cardiovascular Rise

\section{INTRODUCTION}

Almost half of the vascular events appear in individuals with normal lipidemic profile. However, the classic preventive anti-lipidemic treatment is indicated only for individuals with hyperlipidemia. There are studies which have demonstrated that a preventive treatment could be administered to people with normal cholesterol levels but increased levels of C-reactive protein (CRP) [1].

Elevated levels of low density lipoprotein (LDL) are considered to participate in the atherogenic process. Once deposited in the intima, LDL is subjected to chemical modifications, such as oxidatation. The oxidated form of LDL up-regulates a number of molecules which trigger the adherence of monocytes and T-lymphocytes to the endothelial cells of the arterial wall. After the monocytes and T-lymphocytes bind to the arterial surface, they migrate into the subendothelial space, where they differentiate and are transformed into macrophages and foam cells. The oxidated LDL acts as a chemoattractant for monocytes and lymphocytes and it can also inhibit the macrophage mobility. Moreover, the oxidated LDL can stimulate the production of many inflammatory mediators from other vascular cells, resulting in the promotion of the inflammation process. The above actions, among other atherogenic effects, contribute to the formation of the atherosclerotic plaque [2].

Statins act by inhibiting the activity of the 3-hydroxy3-methylglutaryl-coenzyme A (HMG-CoA) reductase. The latter is an enzyme which participates in the regulation of the hepatic synthesis of cholesterol. Statins are more effective in reducing LDL-cholesterol but less drastic in lowering triglycerides and raising HDL-cholesterol. They reduce the incidence of the atherosclerotic events and are used for primary and secondary prevention against cardiovascular episodes. It is believed that statins may also have an anti-thrombotic and anti-inflammatory effect $[3,4]$.

CRP is a sensitive marker of inflammation. In humans, 
the plasma levels of CRP may rise rapidly and extendedly, as much as 10,000-fold or more, after an acute inflammatory stimulus [5]. CRP is mostly synthesized in the hepatocytes but there is recent evidence which demonstrates the extrahepatic production of CRP in different cells including atherosclerotic lesions [6]. It is one of the at least 40 plasma proteins which are defined as acute phase proteins. Their plasma concentration increases or decreases by at least $25 \%$ during an inflammatory process [7]. In recent years, there is plenty of published data which demonstrates a clinical significance of the raised plasma levels of CRP for the evaluation of the cardiovascular risk in apparently healthy individuals. It is recommended [8] that cut-off levels of high-sensitivity $\mathrm{CRP}<1.0,1.0$ to 3.0 and $>3.0 \mathrm{mg} / \mathrm{L}$ express low, average and high risk respectively for the development of cardiovascular disease, even among apparently healthy individuals with low-to-normal lipid levels. These raised levels may reflect an underlying chronic inflammation of the endothelium. In addition, CRP itself may participate actively in the pathogenesis of atherosclerosis through biological effects on the endothelial cells, the monocytes-macrophages and the smooth muscle cells $[9,10]$. Therefore, CRP can constitute a biomarker for the clinical estimation of the cardiovascular disease risk [11]. However, CRP cannot be considered as a specific prognostic marker of ischemic incidents, since it is produced in almost all the forms of inflammation, infection and tissue damage.

According to the National Cholesterol Education Program Guidelines, the desirable LDL levels in people of high risk must be under $70 \mathrm{mg} / \mathrm{dL}$ [12]. The indication for treatment with statins concerns all the individuals of high cardiovascular risk, the individuals of moderate risk with $\mathrm{LDL}>135 \mathrm{mg} / \mathrm{dL}$ and the individuals of low risk with $\mathrm{LDL} \geq 190 \mathrm{mg} / \mathrm{dL}$ [13]. Although the statin therapy is firmly established [14-17] and generally acceptable for secondary prevention, the use of statins for primary prevention remains a controversial subject $[18,19]$.

The JUPITER trial [20] demonstrated that the administration of rosuvastatin in apparently healthy individuals with $\mathrm{LDL}<130 \mathrm{mg} / \mathrm{dL}$ and CRP $>2 \mathrm{mg} / \mathrm{L}$ reduced the LDL levels by $50 \%$ as well as the ischemic vascular incidents approximately by the same percentage. The CRP levels were also reduced by $37 \%$ [21]. This trial tried to answer the question whether individuals of this category (normal LDL, increased CRP) would be benefited by statins. There are also other studies which have demontrated that statins lower the CRP levels [22-24]. The assumption that atherosclerosis is partly an inflammatory process affected also by LDL could justify the use of statins to individuals non-hyperlipidemic and without any indications of vascular disease for primary preven- tion, using the raised CRP levels as a criterion for the initiation of the treatment. Therefore, the benefits from statins may extend beyond the LDL reduction alone. At this point, a critical question emerges. Are the LDL levels independent of CRP levels? The present study aims at the demonstration of the existence or not of a possible correlation between LDL and CRP among apparently healthy individuals with normal LDL and the comparison of the mean CRP values between individuals with normal CRP and individuals with increased CRP.

\section{MATERIAL-METHODS}

The material of the study includes a series of LDL and CRP test results from the records of the laboratorial examinations of the Microbiological Laboratory of the Regional Department of N. Kosmos of the Social Insurance Institute in the city of Athens from 2008 through 2010. The study population was divided in two groups. The first group included 260 adult men (mean age 48 years old, mean weight $85 \mathrm{~kg}$, and mean height $1.72 \mathrm{~m}$ ) and 484 adult women (mean values 48 years old, $85 \mathrm{~kg}$, and $1.62 \mathrm{~m}$ respectively) whose LDL values were lower than $130 \mathrm{mg} / \mathrm{dL}$ or equal to $130 \mathrm{mg} / \mathrm{dL}$. All the subjects of the first group were clinically healthy without any kind of inflammatory disease. The second group included 60 men and 204 women with LDL higher than $130 \mathrm{mg} / \mathrm{dL}$ and it was used for comparison purposes. The study was approved by the Administration of the Institution and conducted after the issuing of the relative authorization.

The correlation between LDL and CRP was investigated among the individuals with a range of LDL values $\leq 130 \mathrm{mg} / \mathrm{dl}$, separately in men, women and total. The determination of the LDL limit was based on the JUPITER study, according to which the coexistence of a CRP value $>2 \mathrm{mg} / \mathrm{dl}$ is considered by certain clinical physicians as a situation with increased cardiovascular risk and imposes the initiation of a treatment with statins. In addition, the mean values of CRP in the two study groups were assessed and compared.

The appropriate statistical values of LDL and CRP (mean, minimum, maximum, median, mode and standard deviation) among the study population as well as the statistical comparisons were calculated with the use of the statistical package SPSS 14.0 (Copyright (C) SPSS Inc.).

The total cholesterol values were measured with the CHO-POD Timber reaction method, the triglycerides values with a photometrical (GPO-PAP) determination, the HDL values with the immunoinhibition technique and the CRP values with the method of turbidimetry. The LDL values were calculated automatically according to the formula "LDL $=$ (total cholesterol-triglyc- 
erides)/5-HDL". Tests with triglyceride values over $400 \mathrm{mg} / \mathrm{dl}$ were excluded. The form of the distributions of the LDL and CRP values in the first group was examined and the Pearson's correlation coefficient was calculated. The statistical comparisons were performed with a

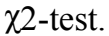

\section{RESULTS}

Table 1 presents the various statistical variables of the of the LDL and CRP values of in the first group (individuals with $\mathrm{LDL} \leq 130 \mathrm{mg} / \mathrm{dL}$ ) of the study population. The average LDL value in the specific group was 95 $\mathrm{mg} / \mathrm{dL}(89 \mathrm{mg} / \mathrm{dL}$ in men and $98 \mathrm{mg} / \mathrm{dL}$ in women), whereas the average CRP value in the same group was $0.93 \mathrm{mg} / \mathrm{L}(0.83 \mathrm{mg} / \mathrm{L}$ in men and $0.99 \mathrm{mg} / \mathrm{L}$ in women $)$. The mean CRP value in the entire second group (individuals with $\mathrm{LDL}>130 \mathrm{mg} / \mathrm{dL})$ was $0.90 \mathrm{mg} / \mathrm{L}(\mathrm{SD} \pm$ 0.75). Table 2 shows the Pearson's correlation coefficients in the three subcategories (men, women, total) of the first study group. It was found that the Pearson's

Table 1. Statistical data of the LDL and CRP values in the first group (individuals with $\mathrm{LDL} \leq 130 \mathrm{mg} / \mathrm{dL}$ ) of the study population (264 men and 484 women).

\begin{tabular}{|c|c|c|c|}
\hline Statistical variables & Sex & $\mathrm{LDL}(\mathrm{mg} / \mathrm{dL})$ & $\mathrm{CRP}(\mathrm{mg} / \mathrm{L})$ \\
\hline \multirow{3}{*}{ Mean } & Men & 89 & 0.83 \\
\hline & Women & 98 & 0.99 \\
\hline & Total & 95 & 0.93 \\
\hline \multirow{3}{*}{ Median } & Men & 91 & 0.60 \\
\hline & Women & 103 & 0.70 \\
\hline & Total & 101 & 0.70 \\
\hline \multirow{3}{*}{ Mode } & Men & 55 & 0.50 \\
\hline & Women & 118 & 0.60 \\
\hline & Total & 118 & 0.60 \\
\hline \multirow{3}{*}{ Standard deviation } & Men & 25 & 0.82 \\
\hline & Women & 23 & 1,22 \\
\hline & Total & 24 & 1,02 \\
\hline \multirow{3}{*}{ Minimum } & Men & 41 & 0.10 \\
\hline & Women & 39 & 0.01 \\
\hline & Total & 39 & 0.01 \\
\hline \multirow{3}{*}{ Maximum } & Men & 127 & 5.90 \\
\hline & Women & 130 & 10.20 \\
\hline & Total & 130 & 10.20 \\
\hline
\end{tabular}

Table 2. Pearson's coefficient in the first group (264 men and 484 women, $\mathrm{LDL} \leq 130 \mathrm{mg} / \mathrm{dL}$ ).

\begin{tabular}{|c|c|c|c|c|}
\hline & & & LDL & CRP \\
\hline \multirow{7}{*}{ Male } & \multirow{4}{*}{ LDL } & Pearson & 1 & 0.120 \\
\hline & & p-Value* & - & 0.339 \\
\hline & & $\mathrm{N}$ & 264 & 264 \\
\hline & & Dorsch & 0120 & 1 \\
\hline & \multirow{3}{*}{ CRP } & & & \\
\hline & & p-Value* & 0.339 & - \\
\hline & & $\mathrm{N}$ & 284 & 284 \\
\hline \multirow{6}{*}{ Female } & \multirow{4}{*}{ LDL } & Pearson & 1 & -0.073 \\
\hline & & p-Value* & - & 0.425 \\
\hline & & Apt $\theta \mu$ ós & 484 & 484 \\
\hline & & Pearson & $-0.0,73$ & 1 \\
\hline & \multirow[t]{2}{*}{ CRP } & p-Value* & 0.425 & - \\
\hline & & $\mathrm{N}$ & 484 & 484 \\
\hline \multirow{7}{*}{ Total } & \multirow{4}{*}{ LDL } & Pearson & 1 & -0.008 \\
\hline & & p-Value* & - & 0.917 \\
\hline & & $\mathrm{N}$ & 748 & 748 \\
\hline & & & & \\
\hline & \multirow{3}{*}{ CRP } & Pearson & -0.008 & 1 \\
\hline & & p-Value* & 0.917 & - \\
\hline & & $\mathrm{N}$ & 748 & 748 \\
\hline
\end{tabular}

correlation coefficient was 0.120 in males (p-Value $0.339),-0.073$ in females (p-Value 0.425 ) and -0.008 in total (p-Value 0.917).

\section{DISCUSSION}

\subsection{Main Discussion}

The generative effect of LDL in atherosclerosis and the pathogenic role of CRP either as an inflammation marker or as a contributor to the atherogenic process are acceptable to a great extend by the scientific community. The initiation of a treatment with statins in people with normal LDL levels $(\leq 130 \mathrm{mg} / \mathrm{dL})$ but increased CRP levels $(>2.0 \mathrm{mg} / \mathrm{L})$ is currently a research subject with controversial opinions. The results of the present study showed there is not a correlation between the LDL and CRP values among the study groups' populations. It is being discussed whether certain factors interfere in this conclusion.

The process of inflammation can be considered as a body reaction to the destruction of architectural structure of the vascular endothelium. In turn, inflammation 
represents a significant factor which leads to the formation of atherosclerotic lesions and favors both the destabilization of the atheromatic plaque and the formation of thrombi [25]. It is assumed that various factors could differentiate selectively the sensitivity of the vascular endothelium or affect in various ways the organism's reaction to the "toxic" influence of LDL.

According to the Pearson's correlation coefficient ( 0.120 in males, -0.073 in females and -0.008 in total), the LDL variations were not being followed by respective variations in the CRP values among the normal LDL group in the present study. That is to say that an LDL increase was not accompanied by a statistically respective CRP increase. Moreover, the comparison of the mean values of CRP in the two study groups (individuals with $\mathrm{LDL} \leq 130 \mathrm{mg} / \mathrm{dL}$ and individuals with $\mathrm{LDL}>130$ $\mathrm{mg} / \mathrm{dL}$ ) showed that there is no statistically significant difference $(\mathrm{P}>0.05)$.

\subsection{Conclusions}

Nowadays, there is a clinical trend which supports the study and use of certain biochemical markers, such as oxidized phospholipids on apolipoprotein B-100 particles $(\mathrm{OxPL} / \mathrm{apoB})$, for the prediction of the development of the atheromatic disease [26]. The findings of the present study could also implicate a clinical significance. They do not reject the initiation of a treatment with statins in individuals with a normal lipidemic profile but increased CRP values ( $>2 \mathrm{mg} / \mathrm{L}$ ), no matter what discussion is being conducted on this field. However, the specific treatment should not be based exclusively on the correlation of the LDL and CRP values, as certain researchers believe, but it should include other criteria too. Definitely, the coexisting increased levels of LDL and CRP constitute a dangerous compound, even if the CRP measurement has not been established as an important marker for the prevention of cardiovascular incidents and it is not included in the ordinary tests, unlike the LDL evaluation. Further studies on this field are certainly necessary for the formation of well established guidelines and the broad application of CRP screening and the initiation of statin therapy or even treatment with ezetimibe [27] in individuals with normal lipidemic profile.

\section{REFERENCES}

[1] Everett, B.M., Glynn, R.J., MacFadyen, J.G. and Ridker, P.M. (2010) Rosuvastatin in the prevention of stroke among men and women with elevated levels of $\mathrm{C}$-reactive protein: justification for the use of statins in prevention: an intervention trial evaluating rosuvastatin (JUPITER). Circulation, 121, 143-150. doi:10.1161/CIRCULATIONAHA.109.874834
[2] Fan, J. and Watanabe, T. (2003) Inflammatory reactions in the pathogenesis of atherosclerosis. Journal of Atherosclerosis and Thrombosis, 10, 63-71.

[3] Stoll, G. and Bendszus, M. (2006) Inflammation and atherosclerosis-novel insights into plaque formation and destabilization. Stroke, 37, 1923-1932. doi:10.1161/01.STR.0000226901.34927.10

[4] Mora, S. and Ridker, P.M. (2006) Justification for the use of statins in primary prevention: an intervention trial evaluating rosuvastatin (JUPITER) - can C-reactive protein be used to target statin therapy in primary prevention? The American Journal of Cardiology, 97, 33A-41A. doi:10.1016/j.amjcard.2005.11.014

[5] Hirschfield, G.M. and Pepys, M.B. (2003) C-reactive protein and cardiovascular disease: new insights from an old molecule. QJM: Monthly Journal of the Association of the Physicians, 96, 793-807.

[6] Venugopal, S.K., Devaraj, S. and Jialal, I. (2005) Effect of C-reactive protein on vascular cells: evidence for a proinflammatory, proatherogenic role. Current Opinion in Nephrology and Hypertension, 14, 33-37. doi:10.1097/00041552-200501000-00006

[7] Black, S., Kushner, I. and Samols, D. (2004) C-reactive protein. The Journal of Biological Chemistry, 279, 48487-48490. doi:10.1074/jbc.R400025200

[8] Pearson, T.A., Mensah, G.A., Alexander, R.W., Anderson, J.L., Cannon, R.O. 3rd, Criqui, M., Fadl, Y.Y., Fortmann, S.P., Hong, Y., Myers, G.L., Rifai, N., Smith, S.C. Jr, Taubert, K., Tracy, R.P. and Vinicor, F. (2003) Markers of inflammation and cardiovascular disease: Application to clinical and public health practice: A statement for healthcare professionals from the Centers for Disease Control and Prevention and the American Heart Association. Circulation, 107, 499-511.

doi:10.1161/01.CIR.0000052939.59093.45

[9] Devaraj, S., Singh, U. and Jialal, I. (2009) The evolving role of C-reactive protein in atherothrombosis. Clinical Chemistry, 55, 229-238. doi:10.1373/clinchem.2008.108886

[10] Jialal, I., Devaraj, S. and Venugopal, S.K. (2004) C-reactive protein: Risk marker or mediator in atherothrombosis? Hypertension, 44, 6-11. doi:10.1161/01.HYP.0000130484.20501.df

[11] Ridker, P.M. (2003) Clinical application of C-reactive protein for cardiovascular disease detection and prevention. Circulation, 107, 363-369. doi:10.1161/01.CIR.0000053730.47739.3C

[12] Grundy, S.M., Cleeman, J.L., Merz, C.N., Brewer, H.B. Jr, Clark, L.T., Hunninghake, D.B., Pasternak, R.C., Smith, S.C. Jr and Stone, N.J. (2004) Implications of recent clinical trials for the National Cholesterol Education Program Adult Treatment Panel III Guidelines. Circulation, 110, 227-239. doi:10.1161/01.CIR.0000133317.49796.0E

[13] Genest, J., McPherson, R., Frohlich, J., Anderson, T., Campbell, N., Carpentier, A., Couture, P., Dufour, R., Fodor, G., Francis, G.A., Grover, S., Gupta, M., Hegele, R.A., Lau, D.C., Leiter, L., Lewis, G.F., Lonn, E., Mancini, G.B., Ng, D., Pearson, G.J., Sniderman, A., Stone, J.A. and Ur, E. (2009) 2009 Canadian Cardiovascular Society/Canadian guidelines for the diagnosis and 
treatment of dyslipidemia and prevention of cardiovascular disease in the adult-2009 recommendations. The Canadian Journal of Cardiology, 25, 567-579. doi:10.1016/S0828-282X(09)70715-9

[14] Heart Protection Study Collaborative Group. (2002) MRC/BHF Heart Protection Study of cholesterol lowering with simvastatin in 20,536 high-risk individuals: a randomised placebocontrolled trial. Lancet, 360, 7-22. doi:10.1016/S0140-6736(02)09327-3

[15] The Long-Term Intervention with Pravastatin in Ischaemic Disease (LIPID) Study Group. (1998) Prevention of cardiovascular events and death with pravastatin in patients with coronary heart disease and a broad range of initial cholesterol levels. The New England Journal of Medicine, 339, 1349-1357. doi:10.1056/NEJM199811053391902

[16] Sacks, F.M., Pfeffer, M.A., Moye, L.A., Rouleau, J.L., Rutherford, J.D., Cole, T.G., Brown, L., Warnica, J.W., Arnold, J.M., Wun, C.C., Davis, B.R. and Braunwald, E. (1996) The effect of pravastatin on coronary events after myocardial infarction in patients with average cholesterol levels. Cholesterol and Recurrent Events Trial investigators. The New England Journal of Medicine, 335, 1001-1009. doi:10.1056/NEJM199610033351401

[17] The Scandinavian Simvastatin Survival Study Group. (1994) Randomised trial of cholesterol lowering in 4444 patients with coronary heart disease: the Scandi navian Simvastatin Survival Study (4S). Lancet, 344, 1383-1389.

[18] Abramson, J. and Wright, J.M. (2007) Are lipid-lowering guidelines evidence-based? Lancet, 369, 168-169. doi:10.1016/S0140-6736(07)60084-1

[19] Ravnskov, U., Rosch, P.J., Sutter, M.C. and Houston, M.C. (2006) Should we lower cholesterol as much as possible? BMJ (Clinical Research ed.), 332, 13301332. doi:10.1136/bmj. 332.7553.1330

[20] Ridker, P.M. and the JUPITER Study Group. (2003) Rosuvastatin in the primary prevention of cardiovascular disease among patients with low levels of low-density lipoprotein cholesterol and elevated high-sensitivity $\mathrm{C}$-reactive protein: rationale and design of the JUPITER trial. Circulation, 108, 2292-2297. doi:10.1161/01.CIR.0000100688.17280.E6

[21] Ridker, P.M., Danielson, E., Fonseca, F.A., Genest, J., Gotto, A.M. Jr, Kastelein, J.J., Koenig, W., Libby, P., Lorenzatti, A.J., MacFadyen, J.G., Nordestgaard, B.G., Shepherd, J., Willerson, J.T., Glynn, R.J. and the JUPITER Study Group (2008) Rosuvastatin to prevent vascular events in men and women with elevated C-reactive protein. The New England Journal of Medicine, 359, 2195-2207. doi:10.1056/NEJMoa0807646

[22] Albert, M.A., Danielson, E., Rifai, N., Ridker, P.M. and the PRINCE investigators (2001) Effect on statin therapy on C-reactive protein levels - the pravastatin inflammation/CRP evaluation (PRINCE): a randomized trial and cohort study. JAMA: The Journal of the American Medical Association, 286, 64-70. doi:10.1001/jama.286.1.64

[23] Ridker, P.M., Rifai, N. and Lowenthal, S.P. (2001) Rapid reduction in C-reactive protein with cerivastatin among 785 patients with primary hypercholesterolemia. Circulation, 103, 1191-1193.

[24] Ridker, P.M., Rifai, N., Pfeffer, M.A., Sacks, F. and Braunwald, E. (1999) Long-term effects of pravastatin on plasma concentration of C-reactive protein. The Cholesterol and Recurrent Events (CARE) Investigators Circulation, 100, 230-235.

[25] Ferri, C., Croce, G., Cofini, V., De Berardinis, G., Grassi, D., Casale, R., Properzi, G. and Desideri, G. (2007) C-reactive protein: interaction with the vascular endothelium and possible role in human atherosclerosis. Current Pharmaceutical Design, 13, 1631-1645. doi:10.2174/138161207780831301

[26] Tsimikas, S. and Miller, Y.I. (2011) Oxidative modification of lipoproteins: mechanisms, role in inflammation and potential clinical applications in cardiovascular disease. Current Pharmaceutical Design, 17, 27-37. doi:10.2174/138161211795049831

[27] Lioudaki, E., Ganotakis, E.S. and Mikhailidis, D.P. (2011) Ezetimibe; more than a low density lipoprotein cholesterol lowering drug? An update after 4 years. Current Vascular Pharmacology, 9, 62-86. doi:10.2174/157016111793744760 